\title{
CORONAVIRUS DISEASE 2019 VACCINATION DRIVE: THE PERCEPTIONS AND ACCEPTANCE OF VACCINATION AMONG HEALTH CARE WORKERS
}

\author{
KASI VISWANATH ${ }^{1 *}$, HIREMATH RN ${ }^{2}$, SHARANJIT SINGH BASRA ${ }^{3}$, NIRAJ CHOUREY ${ }^{4}$, DOBI SRAVAN KUMAR ${ }^{5}$ \\ ${ }^{1}$ Public Health Specialist, Meerut, Upper Pradesh, India. ${ }^{2}$ Public Health Specialist, Bengaluru, Karnataka, India. ${ }^{3}$ Surgical specialist, \\ Amritsar, Punjab, India. ${ }^{4}$ Obstetrician, Babina, Uttar Pradesh, India. ${ }^{5}$ Medical officer, New Delhi, India.
}

Email: dr.kasiviswanath@gmail.com

Received: 25 April 2021, Revised and Accepted: 05 June 2021

ABSTRACT

Objective: Coronavirus disease 2019 (COVID-19) infection evolved as a worst nightmare across entire humanity especially for health care workers along with all stakeholders of the society ever since the beginning of year 2020. Vaccination campaign is one of the most successful public health interventions and a cornerstone for the prevention of communicable infectious diseases. To have a baseline data and to form the basis for further vaccination drive, we carried out this study with an objective to understand the perception and COVID-19 vaccine hesitancy among health care workers (HCWs).

Methods: A correctional study was carried out at one of the multispecialty hospital in North India where COVID-19 vaccination for HCWs was planned and 675 HCWs were taken into the study. Data were collected by means of personal interview using pretested semi-structured questionnaire and Epi Info version 6 was used for analysis.

Results: The mean age of the participants was 32.78 years. Majority were male (89.48\%), working in government sector (87.7\%) and paramedic (88.15\%). While $94.67 \%$ were accepting vaccine voluntarily while remaining were not confident enough on their own, only $26.96 \%$ were ready to take vaccine even on payment. The overall awareness scores of study participants were calculated and found that 79.56\% of them had poor awareness level while only $20.44 \%$ had satisfactory awareness level. The association of awareness score was statistically significant with job profile (designation), gender, and prior COVID-19 positivity of study participants.

Conclusion: The decision of vaccine prioritization to HCWs and frontline workers will boost the morale and spirit of warriors high in future. This study was a preliminary attempt to check any vaccine hesitancy factors among HCWs and act accordingly. Although almost all had volunteered for vaccine, the knowledge about vaccine was poor in majority of HCWs as the time period was recent to vaccine rollout and detailed research findings were not yet out about vaccine. All measures to be taken including intensive information education and communications activities targeting HCWs and general population on regular basis to upgrade the knowledge on vaccine issues. A strong communicating policy in an era of misinformation is highly recommended as social media plays an important role in spreading true as well as false messages jeopardizing the entire gains of successful vaccination and attainment of herd immunity. Heath Care Workers to act as role model for general public and patients, which would in turn increase the vaccine acceptance.

Keywords: Coronavirus, Health care workers, Perceptions, Vaccination

(c) 2021 The Authors. Published by Innovare Academic Sciences Pvt Ltd. This is an open access article under the CC BY license (http://creativecommons.org/ licenses/by/4.0/) DOI: http://dx.doi.org/10.22159/ajpcr.2021v14i6.41971. Journal homepage: https://innovareacademics.in/journals/index.php/ajpcr

\section{INTRODUCTION}

Coronavirus disease 2019 (COVID-19) is super-infectious disease caused by severe acute respiratory syndrome coronavirus 2 (SARSCoV-2). COVID-19 infection evolved as a worst nightmare across entire humanity especially for health care workers (HCWs) along with all stakeholders of the society ever since the beginning of year 2020, when the World Health Organization (WHO) declared it as pandemic with rising infection rate and severity across the world. This virus caused respiratory illness ranging from the common cold to severe disease. It caused illness across all age group but severely affected older people and those with underlying medical problems such as cardiovascular disease, diabetes, chronic respiratory disease, and cancer [1]. It was first identified in Wuhan, China, in December 2019 and is an on-going pandemic. In India, the first case reported in Kerala state in January 2020 , being novel virus there was no specific treatment and vaccine till end of year 2020 .

The control of COVID-19 is a huge challenge due to fear of unknown, India was quick to close its international borders and enforce an immediate lockdown [2] for emergency preparedness and response. As of December 27, 2020, there have been over 79.2 million cases and over 1.7 million deaths reported globally since the start of the pandemic, whereas in India, alone total cumulative cases were over $10,187,850$ and 147,622 deaths reported [3]. There is significant reduction of HCWs capacity through periods of infection by quarantine, isolation guidelines, and round the clock hectic work schedule under stress.

After various public health measures such as nation-wide lockdown, containment zones, isolation centers, quarantine centers to simple social distancing, masking, and hand washing, the world was eagerly waiting for vaccination campaign which is one of the most successful public health interventions and a cornerstone for the prevention of communicable infectious diseases. Notwithstanding vaccine progress, ongoing public acceptance is required to maintain herd immunity, prevent outbreaks of vaccine preventable illnesses, and ensure adoption of novel vaccines [2]. Any new vaccine introduction in short period of span creates lots of doubts and hesitancy among both HCWs and general public as we have seen in H1N1 infection too [4]. Vaccine hesitancy refers to delay in acceptance or refusal of vaccination despite availability of vaccination services. Vaccine hesitancy is complex and context specific, varying across time, place, and vaccines. It is influenced by factors such as complacency, convenience, and confidence [5]. Vaccine hesitancy will create isolation from vaccination for any individual when they triggered by variety of unknown sources of information either through social media or message sharing messengers without health 
editorial oversight [6], which is extreme potential threat to public health interventional strategies. The simple forward of message leads full throated castigation which compromises the vaccine development for novel viruses.

At one side, HCWs are strongest influencers in vaccination decisions as common population and patients show greater resistance to accept novel vaccines [7], on the other side, COVID-19 pandemic has reminded all of us of the vital role health workers played to relieve suffering and save lives. Thus, recognizing health worker safety as a priority for patient safety, WHO Member States, and all relevant stakeholders urged to take urgent and sustainable action and in the context of emergency response, giving health workers priority access to newly licensed and available vaccines [8].

The union Health Ministry of India advised all states to commence COVID-19 vaccination drive to HCWs on January 16, 2021, as priority one and approved two vaccines for restricted emergency use in India [9]. The massive Phase 1 vaccination drive carried out with "Covishield manufactures by Serum Institute of India" and indigenously developed "Covaxine" of Bharat Biotech which has been offered two doses for free of cost to all HCWs and frontline workers (FLWs).

In view of above, to have a baseline data and to form the basis for further vaccination drive, we carried out this study with an aim to understand the perception and COVID-19 vaccine hesitancy among HCWs. At our study area, Covishield vaccine was provided by Government of India to all HCWs. COVISHIELD is ChAdOx1-S/nCoV-19 (recombinant) vaccine which again is a recombinant vaccine with replication deficient chimpanzee adenovirus vector encoding the SARS-COV-2 spike glycoprotein. The vaccine is genetically modified in human embryonic kidney 293 cells [10].

\section{METHODS}

A correctional study was carried out at one of the multispecialty hospital in North India where COVID-19 vaccination for HCWs was planned. COVID-19 vaccination was planned for approximately 1010 HCWs with target of 100-150 per day. About $95 \%$ of vaccination was achieved in 10 days. On each day before inoculation, pre-tested semi-structured questionnaire was used to gather information about awareness and vaccine acceptance/hesitancy among HCWs and data were collected by means of personal interview.

Expecting the vaccine acceptance and awareness rate of $50 \%$, alpha $5 \%$, and chance error $5 \%$, the sample size calculated was 385 . However, since 675 HCWs were willing for the study and gave consent, 675 HCWs were taken into the study. All those who refused for consent and unwilling were excluded from study. Data collected were entered into Excel sheet and Epi Info version 6 was used for analysis. Chi-square was used for proportions comparison at statistical significance at $\mathrm{p}<0.05 \%$. To assess collective awareness, set of 12 questions was selected. One mark for given for right answer and zero mark for wrong. Total scores were divided into two categories, poor awareness ( $<50 \%$ marks $)$ and satisfactory awareness (more than 50\% marks).

\section{RESULTS}

The mean age of the participants was 32.78 years. Majority were male $(89.48 \%)$, working in government sector $(87.7 \%)$ and paramedic (88.15\%) (Table 1). About 41 (6.07\%) of the participants have suffered with COVID-19 earlier with $2(0.30 \%)$ of them suffered 6 months ago and $39(5.78 \%)$ of them suffered 3 months ago. Thirty-two (4.74\%) of them had symptoms related to COVID-19 but not tested while one had their family member with COVID-19-related symptoms earlier. All of them $675(100 \%)$ knew about two variety of vaccines but only $130(19.26 \%)$ knew about the correct type of vaccine available at their center before being administration, implying that irrespective of type of vaccine, all HCWs were ready to take vaccine, which was a good sign of vaccine acceptance.
About $100 \%$ knew about two variety of vaccines launched by government and $19.26 \%$ knew about the type of vaccines allotted to HCWs at their center. When asked about benefits of taking COVID-19 vaccine, $100 \%$ said that it will protect us from COVID-19 infection while $64.59 \%$ of them said that it protects family members too. About $74.67 \%$ said that both vaccines are equally effective while $19.26 \%$ said that Covisheild is better than Covaxine. When asked about reasons for thinking the vaccine is best, $27.70 \%$ told it's because of lesser side effects, easy availability (4.74\%), and good efficacy (9.93\%) (Table 2). Majority $(62.67 \%)$ did not know about when immunity is achieved after taking vaccine while $23.85 \%$ told that they will be immune within 1-2 weeks. Surprisingly, $31.26 \%$ told that vaccine is effective against mutant strains while $36.30 \%$ did not know anything about it. Majority of them rightly knew about side effects which included pain (96.15\%), fever $(65.48 \%)$, allergic reactions $(48.04 \%)$, and paralysis (8.15\%). Even at this point when cases and deaths are declining in this country, $49.19 \%$ HCWs agreed that vaccine is required and $26 \%$ felt that vaccine is required even for those who contracted COVID-19 disease earlier

While $94.67 \%$ were accepting vaccine voluntarily while remaining were not confident enough on their own, only $26.96 \%$ were ready to take vaccine even on payment (Table 3 ).

The overall awareness scores of study participants were calculated and found that $79.56 \%$ of them had poor awareness level while only $20.44 \%$ had satisfactory awareness level (Fig. 1). The association of awareness score was statistically significant with job profile (designation), gender, and prior COVID-19 positivity of study participants (Table 5).

Table 1: Sociodemographic profile of study participants

\begin{tabular}{lll}
\hline Gender & Frequency & Percent \\
\hline Female & 71 & 10.52 \\
Male & 604 & 89.48 \\
Age category & & \\
<25 years & 148 & 21.93 \\
25-35 years & 309 & 45.78 \\
35-45 years & 151 & 22.37 \\
Above 45 years & 67 & 9.93 \\
Job category & & \\
Government & 592 & 87.70 \\
Private & 83 & 12.30 \\
Designation & & \\
Medical officer & 38 & 5.63 \\
Nursing staff & 42 & 6.22 \\
Paramedic & 595 & 88.15 \\
Total & 675 & 100.00 \\
\hline
\end{tabular}

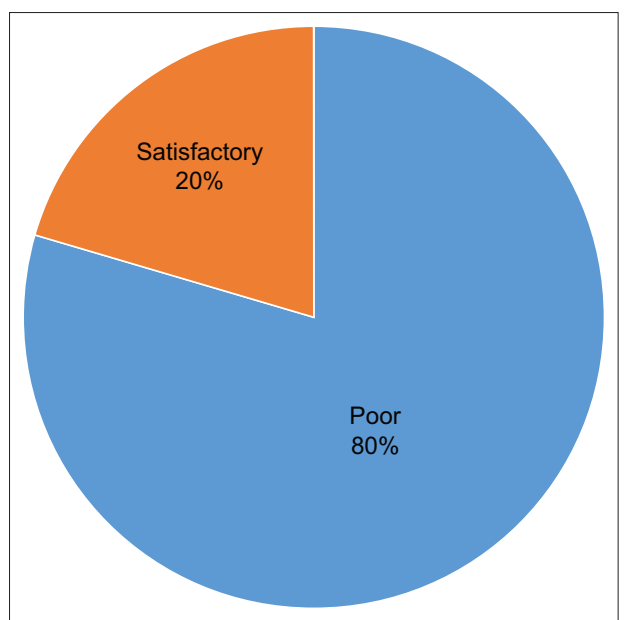

Fig. 1: Awareness level among study participants 


\section{DISCUSSION}

Ever since the COVID-19 pandemic, countries across the world were trying hard for an effective vaccine. Finally, vaccines of Moderna, Pfizer BioNtech, and Oxford Astrazeneca were recently approved [11]. India also approved two vaccines on January 3,2021, for restricted use under emergency [9] and finally vaccination drive for high-risk individuals was started on January 16, 2021, for HCWs. This study was carried out between January 16, 2021, and January 30, 2021, among HCWs at the COVID-19 vaccination center before getting vaccinated. Our study was

Table 2: Awareness regarding available COVID-19 vaccine in India

\begin{tabular}{lcl}
\hline Variables & Frequency (n=675) & Percent \\
\hline Best available vaccine in India (vaccine effectiveness) & \\
Covaxine & 41 & 6.07 \\
Covishield & 130 & 19.26 \\
Both & 504 & 74.67 \\
Reasons for thinking this vaccine is best & \\
Do not know & 389 & 57.63 \\
Easily available & 32 & 4.74 \\
Good efficacy & 67 & 9.93 \\
Less side effects & 187 & 27.70 \\
After getting vaccine, immunity is achieved & \\
After 3-5 weeks & 46 & 6.81 \\
After 6-8 weeks & 20 & 2.96 \\
After 8 weeks & 25 & 3.70 \\
Do not know & 423 & 62.67 \\
Within 1-2 weeks & 161 & 23.85 \\
Does vaccine effective against mutant strains & \\
Do not know & 245 & 36.30 \\
No & 219 & 32.44 \\
Yes & 211 & 31.26 \\
Vaccine side effects & & \\
Pain & 649 & 96.15 \\
Paralysis & 55 & 8.15 \\
Allergic reaction & 332 & 68.04 \\
Fever & 442 & - \\
Others & - & \\
\hline CoviD-19: Coronavirus disease 2019 & \\
\hline
\end{tabular}

Table 3: Acceptance of COVID-19 vaccine among study participants

\begin{tabular}{lll}
\hline Variables & Frequency & Percent \\
\hline Acceptance for vaccine & & \\
voluntarily & & \\
No & 36 & 5.34 \\
Yes & 639 & 94.67 \\
Acceptance for vaccine voluntarily even if available on payment \\
Can't tell, depends on cost & 53 & 7.85 \\
No & 440 & 65.19 \\
Yes & 182 & 26.96 \\
\hline COVID-19: Coronavirus disease 2019 &
\end{tabular}

COVID-19: Coronavirus disease 2019 an effort to see the perceptions of HCWs about vaccine acceptance/ hesitancy as acceptance by HCWs would influence drastically the vaccine acceptance by general population and would act as a role model to others.

In our study, $100 \%$ of participants said that they would continue practices of COVID-19 precautionary measures, even after vaccination also, which was very appreciable. About $80.44 \%$ of participants strongly believed that beneficiaries could spread infection and can get infected $(73.93 \%)$ even after vaccination. When majority believed that they could get infected even after vaccination and can spread infection too, then ideally, they should have understood that quarantine would be essential to some extent even after vaccination but only $43 \%$ of HCWs felt so. This indicates that even HCWs had confused ideas about quarantine basics

\section{Vaccine acceptance}

Vaccine rollout in India was done when COVID-19 cases and deaths were on declining trend. However, majority (49.19\%) of study participants said that vaccine is required irrespective of present COVID-19 scenario, which was a good sign considering the second wave impacting the other countries during this time. Although only $20 \%$ of study participants had satisfactory awareness level, the voluntary acceptance rate for vaccine was very high (94.67\%). Such a high acceptance level was very good and would influence general population also. The low awareness level about vaccine is probably because of vaccination rollout for HCWs was quick and in-depth awareness about vaccine details was low initially as detailed research findings were not yet out about vaccine. We could not find any study in this area, which was immediately carried out on vaccine rollout to assess the acceptance in India, as the authors were quick to carry out this study to see any hesitancy among HCWs so that any need to increase actions in terms of information education and communications (IEC) activities be found out at the earliest. Our study emphasizes the need for regular update of knowledge on vaccinations among HCWs, although it is a novel vaccine but true indepth information about vaccine must be disseminated among HCWs and general populace at the earliest, before any hesitancy is developed among them against vaccine.

Poor awareness score was seen among 83.19\% of paramedic and $61.90 \%$ of nursing staff then compared to medical officers, warranting specific IEC, and regular update to them about all aspects of COVID-19 as the association between designated HCWs and awareness score was statistically significant. Poor awareness level was also seen among $80 \%$ of HCWs who did not have COVID-19 positivity earlier as compared to $68 \%$ of those who had prior COVID-19 positivity. The association between prior COVID-19 positivity status and awareness score was statistically significant. This indicates that HCWs who were COVID positive earlier were showing more interest on gathering information about vaccine than compared to COVID-negative HCWs. Thus, these HCWs should be targeted more.

The study carried out by Al-Qerem and Jarab [12] in Middle Eastern population, showed very low intend (36.8\%) for vaccine even when

Table 4: Graded response of study participants on COVID-19 vaccine (On a visual analog scale ranging from 0 [minimum] to 5 [maximum])

\begin{tabular}{|c|c|c|c|c|c|c|}
\hline \multirow[t]{2}{*}{ Variables } & \multicolumn{6}{|l|}{ Grading (\%) } \\
\hline & $\mathbf{0}$ & 1 & 2 & 3 & 4 & 5 \\
\hline Vaccine effectiveness & - & - & - & $116(17.19)$ & $208(30.81)$ & $351(52.00)$ \\
\hline Vaccine side effects & $366(54.22)$ & $174(25.78)$ & $135(20.00)$ & - & - & - \\
\hline $\begin{array}{l}\text { Requirement of taking vaccine by person who is } \\
\text { previously COVID positive }\end{array}$ & $31(4.59)$ & $176(26.07)$ & 332 (49.19) & $136(20.15)$ & - & - \\
\hline
\end{tabular}

COVID-19: Coronavirus disease 2019 
Table 5: Association of awareness scores and different variables of study participants

\begin{tabular}{|c|c|c|c|}
\hline \multirow{2}{*}{$\begin{array}{l}\text { Selected } \\
\text { parameters }\end{array}$} & \multicolumn{2}{|c|}{ Awareness score (\%) } & \multirow[t]{2}{*}{ p-value } \\
\hline & Poor & Satisfactory & \\
\hline \multicolumn{4}{|l|}{ Designation } \\
\hline Medical officer & $16(42.11)$ & $22(57.89)$ & \multirow{3}{*}{$\mathrm{p}=0.00$} \\
\hline Nursing staff & $26(61.90)$ & $16(38.10)$ & \\
\hline Paramedic & 495 (83.19) & $100(16.81)$ & \\
\hline \multicolumn{4}{|l|}{ Age category } \\
\hline$<25$ years & $120(81.08)$ & 28 (18.92) & \multirow{4}{*}{$\mathrm{p}=0.96$} \\
\hline $25-35$ years & 245 (79.29) & $64(20.71)$ & \\
\hline $36-45$ years & $119(78.81)$ & 32 (21.19) & \\
\hline Above 45 years & $53(79.10)$ & $14(20.90)$ & \\
\hline \multicolumn{4}{|l|}{ Gender } \\
\hline Female & $50(70.42)$ & $21(29.58)$ & \multirow[t]{2}{*}{$\mathrm{p}=0.02$} \\
\hline Male & 487 (80.63) & 117 (19.37) & \\
\hline \multicolumn{4}{|l|}{$\begin{array}{l}\text { Prior COVID-19 } \\
\text { positivity status }\end{array}$} \\
\hline No & $509(80.28)$ & 125 (19.72) & \multirow[t]{3}{*}{$\mathrm{p}=0.03$} \\
\hline Yes & $28(68.29)$ & $13(31.71)$ & \\
\hline Total & 537 (79.56) & $138(20.44)$ & \\
\hline
\end{tabular}

COVID-19: Coronavirus disease 2019

the cases in their region increased rapidly during that time compared to our study where vaccine acceptance was very high even when cases and death rates were low, implying our HCWs had better acceptance than other. The acceptance level of our HCWs was much higher when compared to global survey that included participants from 19 countries (71\%) [13] and studies carried out in Saudi Arabia (64\%) [14], France (76\%) [15], China (91\%) [16], Ecuador (97\%) [17], and the United States (57\%) [18].

In our study, although $94.67 \%$ had vaccine acceptance voluntarily, $80 \%$ of males had poor awareness scores than compared to female $(70.42 \%)$ and the association between gender and awareness scores was statistically significant $(\mathrm{p}=0.02)$. This is contrary to the findings of $\mathrm{Al}$-Qerem and Jarab [12] in Middle Eastern population along with other studies carried out in Europe [19], China [16], and France [15] were in females had less intent for vaccination. Studies also showed predictors age [15] and income $[15,19]$ as predictors for low intent for vaccination. $\mathrm{Al}$-Qerem and Jarab [12] showed being female, education up to postgraduate degree and being married were predictors for vaccination intention while in our study, designation, gender, and prior COVID-19 positivity were significant predictors for COVID-19 vaccine awareness scores. While all these above studies were on mixed population (nonHCWs and HCWs), our study was mainly on HCWs.

\section{Vaccine acceptance barriers}

In this study, although there were no vaccine acceptance barriers as almost all volunteered for vaccine, $80 \%$ of study participants had poor awareness scores which was of high concern. The awareness level as well as understanding the concepts of vaccination, COVID-19 protocols and related mechanism of action are very important for all HCWs as they play a lead role in implementing and making general population as well as patients aware and motivate them for vaccination. All HCWs need to have adequate knowledge on vaccine efficacy and side effects. In our study, graded response of study participants on COVID-19 vaccine (on a visual analog scale ranging from 0 [minimum] to 5 [maximum]) was assessed, as shown in Table 4 . About $52.00 \%$ graded five with respect to vaccine effectiveness, $66.37 \%$ graded five for requirement of vaccine based on current scenario, $54.22 \%$ graded zero for vaccine side effects while $49 \%$ graded two for requirement of taking vaccine by person who is previously COVID positive. Concerns of vaccine side effects and efficacy are across the world. Al-Qerem and Jarab [12] also showed, vaccine concerns were the main reason for hesitancy or refusal among study participants. Even in studies carried out at China [16], Europe [16], and the United states [18], study participants had concerns about vaccine safety and efficacy. The concerns about vaccine are highly justifiable as countries are fast tracking the manufacturing of vaccine with results based on clinical trials. The most important is the information warfare. Lots of vaccine misinformation do persists in social media as fake messages. Such fake messages should be identified and removed and only realistic true information to be made available to all, through social media and IEC activities to be carried out on regular basis which would improve the vaccine acceptance and remove the hesitancy. Various studies have suggested approaches to tackle vaccine hesitancy [20,21]. For example, Arede et al. suggested that main issues concerning hesitancy were vaccine concerns, plus personal and societal factors. The authors suggested best approaches including long-term approach that involves targeting different age groups on vaccine basics and nullifying the floating false messages. The general population along with HCWs should be made to understand that approved vaccines are safe and go through thorough evaluations, risk and benefit assessment checks. Herd immunity can eliminate diseases in which vaccination plays an important role as evident by various communicable diseases [21].

As per the latest report on February 24, 2021, of Johns Hopkins Bloomberg School of Public Health, in a survey carried out from 23 countries, there was overall drop in COVID-19 vaccine acceptance with increased acceptance in nine countries [22]. Since vaccination is critical part to end COVID-19 pandemic, all measures to be taken on regular basis to increase vaccine acceptance rate. This needs a strong communicating policy in this era of misinformation.

\section{CONCLUSION}

The decision of vaccine prioritization to HCWs and FLWs will boost the morale and spirit of warriors high in future. This study was a preliminary attempt to check any vaccine hesitancy factors among HCWs and act accordingly. Although almost all had volunteered for vaccine, the knowledge about vaccine was poor in majority of HCWs as the time period was recent to vaccine rollout and detailed research findings were not yet out about vaccine. All measures to be taken including intensive IEC activities targeting HCWs and general population on regular basis to upgrade the knowledge on vaccine issues. A strong communicating policy in an era of misinformation is highly recommended as social media plays an important role in spreading true as well as false messages jeopardizing the entire gains of successful vaccination and attainment of herd immunity. HCWs to act as role-model for patients as well as general public to increase the vaccine acceptance rate among them.

\section{ACKNOWLEDGMENTS}

I acknowledge and thank to all my coauthors and study participants.

\section{AUTHORS' CONTRIBUTIONS}

All authors have contributed to the preparation of manuscript.

\section{CONFLICTS OF INTEREST}

Nil.

\section{AUTHORS' FUNDING}

Nil.

\section{REFERENCES}

1. World health Organization. Coronavirus Disease (COVID-19) Advice for the Public. Geneva: World Health Organization; 2020. Available from: https://www.who.int/emergencies/diseases/novelcoronavirus-2019. [Last accessed on 2021 Feb 20].

2. The Lancet. India under COVID-19 lockdown. Lancet 2020;395:1315.

3. COVID-19 Coronavirus Pandemic. Status. Available from: https:// www.worldometers.info/coronavirus. [Last accessed on 2020 Dec 27].

4. Hiremath RN, Atul Kotwal SM, Kunte R, Hiremath S, Basannar D, Bhalla S. Acceptance of vaccination against the 2009 pandemic influenza a among health-care workers in Pune, Maharashtra. Indian J 
Public Health 2013;57:48-9.

5. Paterson P, Meurice F, Stanberry LR, Glismann S, Rosenthal SL, Larson HJ. Vaccine hesitancy and healthcare providers. Vaccine 2016;34:6700-6.

6. Puri N, Coomes EA, Haghbayan H, Gunaratne K. Social media and vaccine hesitancy: New updates for the era of COVID-19 and globalized infectious diseases. Hum Vaccin Immunother 2020;16:2586-93.

7. Wiley KE, Massey PD, Cooper SC, Wood N, Quinn HE, Leask J. Pregnant women's intention to take up a post-partum pertussis vaccine, and their willingness to take up the vaccine while pregnant: A cross sectional survey. Vaccine 2013;31:3972-8.

8. World Health Organization. World Patient Safety Day. Geneva: World Health Organization; 2020. Available from: https://www.who. int/campaigns/world-patient-safety-day/2020. [Last accessed on $2021 \mathrm{Feb} 20]$.

9. Press Statement by the Drugs Controller General of India (DCGI) on Restricted Emergency Approval of COVID-19 Virus Vaccine. PIB GOI; 2021 Available from: https://www.pib.gov.in/PressReleseDetail. aspx?PRID=1685761. [Last accessed on 2021 Feb 20].

10. World Health Organization. Astra Zeneca ChAdOx1-S/n CoV-19, COVID-19 Vaccine. Geneva: World Health Organization; 2021. Available from: https:/www.who.int/publications/m/item/chadox1-srecombinant-covid-19-vaccine. [Last accessed on 2021 Feb 20].

11. COVID-19 Vaccine. Vaccine Safety, Distribution and FAQs/UC Health. Available from: https://www.uchealth.org/services/infectiousdiseases/coronavirus-covid-19/covid-19-vaccine. [Last accessed on 2021 Feb 20].

12. Al-Qerem WA, Jarab AS. COVID-19 vaccination acceptance and its associated factors among a Middle Eastern population. Front Public Health 2021;9:632914.

13. Lazarus JV, Ratzan SC, Palayew A, Gostin LO, Larson HJ, Rabin K, et al. A global survey of potential acceptance of a COVID-19 vaccine. Nat Med 2020;27:225-8.

14. Al-Mohaithef M, Padhi BK. Determinants of COVID-19 vaccine acceptance in Saudi Arabia: A web-based national survey. J Multidiscip Healthc 2020;13:1657-63.

15. Ward JK, Alleaume C, Peretti-Watel P. The French public's attitudes to a future COVID-19 vaccine: The politicization of a public health issue. Soc Sci Med 2020;265:113414

16. Wang J, Jing R, Lai X, Zhang H, Lyu Y, Knoll MD, et al. Acceptance of COVID-19 vaccination during the COVID-19 pandemic in China. Vaccines 2020;8:482.

17. Sarasty O, Carpio CE, Hudson D, Guerrero-Ochoa PA, Borja I. The demand for a COVID-19 vaccine in Ecuador. Vaccine 2020;38:8090-8.

18. Fisher KA, Bloomstone SJ, Walder J, Crawford S, Fouayzi $\mathrm{H}$, Mazor KM. Attitudes toward a potential SARS-CoV-2 vaccine: A survey of U.S. adults. Ann Intern Med 2020;173:964-73.

19. Neumann-Böhme S, Varghese NE, Sabat I, Barros PP, Brouwer W, van Exel J, et al. Once we have it, will we use it? A European survey on willingness to be vaccinated against COVID-19. Eur J Health Econ 2020;21:977-82.

20. Arede M, Bravo-Araya M, Bouchard É, Gill GS, Plajer V, Shehraj A, et al. Combating vaccine hesitancy: Teaching the next generation to navigate through the post truth era. Front Public Health 2019;6:381.

21. Swingle CA. How do we approach anti-vaccination attitudes? Mo Med 2018;115:180-1.

22. Johns Hopkins Bloomberg School of Public Health. COVID-19 Vaccine Acceptance Falling Globally and, in the U.S., Survey Finds; 2021. Available from: https://www.jhsph.edu/news/news-releases/2021/ covid-19-vaccine-acceptance-falling-globally-and-in-the-us-surveyfinds.html. [Last accessed on 2021 Feb 20]. 